\title{
Effect of prehabilitation on ventilatory efficiency in non-small cell lung cancer patients: A cohort study
}

Francis-Edouard Gravier, PT, MSc, ${ }^{\mathrm{a}, \mathrm{b}}$ Tristan Bonnevie, PT, MSc, ${ }^{\mathrm{a}, \mathrm{b}}$ Fairuz Boujibar, PT, MSc, ${ }^{\mathrm{c} d}$ Clément Médrinal, PT, PhD, ${ }^{\text {bee }}$ Guillaume Prieur, PT, MSc, ${ }^{\text {,e }}$ Yann Combret, PT, MSc, ${ }^{\text {f,g }}$

Jean-François Muir, MD, PhD, ${ }^{\mathrm{a}, \mathrm{b}}$ Antoine Cuvelier, $\mathrm{MD}, \mathrm{PhD},{ }^{\mathrm{b}, \mathrm{d}}$ Jean-Marc Baste, $\mathrm{MD}, \mathrm{PhD},{ }^{\mathrm{c}, \mathrm{h}}$ and David Debeaumont, MD

\section{ABSTRACT}

Objective: Cardiopulmonary exercise testing (CPET) for patients awaiting lung resection for non-small cell lung cancer (NSCLC) has developed considerably in recent years. Pulmonary rehabilitation before surgery (prehabilitation) improves postoperative risk factors such as forced expiratory volume in 1 second and peak oxygen consumption $\left(\mathrm{VO}_{2 \text { peak }}\right)$. Ventilatory inefficiency assessed according to the linear regression of the ratio between the increase in minute ventilation and the expired carbon dioxide flow during $\mathrm{CPET}\left(\mathrm{VE} / \mathrm{VCO}_{2}\right.$ slope $)>35$, is a highrisk factor for postoperative complications. Our objective was to assess the effect of prehabilitation on $\mathrm{VE} / \mathrm{VCO} 2$ slope, and its relationship with $\mathrm{VO}_{2 \text { peak }}$.

Methods: This retrospective cohort study was performed between January 1, 2014 and December 31, 2017 at Rouen University Hospital. One hundred fiftytwo patients with NSCLC awaiting lung surgery who underwent CPET were screened. A total of 50 patients who underwent CPET before and after prehabilitation were included.

Results: VE/ $\mathrm{VCO}_{2}$ slope did not change significantly after prehabilitation (median, 37.1 [25th-75th percentile, 33.8-43.4] vs median, 35.4 [25th-75th percentile, 31.1-40.5]; $P=.09$ ), whereas $\mathrm{VO}_{2 \text { peak }}$ increased significantly (from a median of 13.2 [25th-75th percentile, 11.9-14.7] to a median of 14.8 [25th-75th percentile, $13.1-16.4] \mathrm{mL} / \mathrm{kg} / \mathrm{min})$. The number of patients with a high risk of postoperative complications (ie, $\mathrm{VE} / \mathrm{VCO}_{2}$ slope $>35$ ) did not change significantly after prehabilitation. Cardiorespiratory parameters improved significantly more in patients who underwent at least 15 sessions of ambulatory prehabilitation.

Conclusions: $\mathrm{VE} / \mathrm{VCO}_{2}$ slope, a known predictor of favorable surgical outcomes in patients with NSCLC, did not change with the prehabilitation program used in this study, despite clear improvements in $\mathrm{VO}_{2 \text { peak }}$ and other CPET measures. Larger, prospective studies are needed to confirm the results of this study. ( $\mathrm{J}$

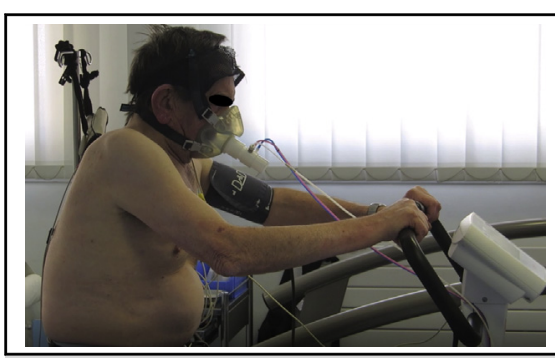

Cardiopulmonary exercise testing before resection for non-small cell lung cancer.

\section{Central Message}

Ventilatory inefficiency, measured according to $\mathrm{VE} / \mathrm{VCO}_{2}$ slope $>35$, is a powerful predictor of complications after lung resection for NSCLC. Unfortunately, prehabilitation did not change $\mathrm{VE} / \mathrm{VCO}_{2}$ slope.

\section{Perspective}

The ambulatory prehabilitation program used in this study did not improve ventilatory efficiency. $\mathrm{VE} / \mathrm{VCO}_{2}$ slope did not improve after training although other physiological parameters did. The subgroup of patients who completed at least 15 sessions benefitted more from the prehabilitation program than those who did not.

See Commentary on page 2513. Thorac Cardiovasc Surg 2019;157:2504-12)

Pulmonary resection surgery is currently the gold standard curative treatment for non-small cell lung cancer (NSCLC) in the early stages of the disease. ${ }^{1}$ However, some patients

From the a ADIR Association, Rouen University Hospital, Rouen, France; ${ }^{\mathrm{b}}$ UPRES EA 3830, Haute Normandie Research and Biomedical Innovation, Normandie University, Rouen, France; ' INSERM U1096, Haute Normandie Research and Biomedical Innovation, Normandie University, Rouen, France; ${ }^{\mathrm{d}}$ Medico-surgical Intensive Care Unit, Jacques Monod Hospital, Le Havre, France; ' Institut de Recherche Expérimentale et Clinique (IREC), Pôle de Pneumologie, ORL and Dermatologie, Université Catholique de Louvain, Brussels, Belgium; ${ }^{\mathrm{f}}$ Physiotherapy Department, Groupe Hospitalier du Havre, Montivilliers, France; ${ }^{\mathrm{g}}$ Thoracic Oncology and Respiratory Intensive Care Department, Rouen University Hospital, Rouen, France; hepartment of Thoracic Surgery, Rouen University Hospital, are unable to tolerate resection because of cardiovascular and respiratory comorbidities or severely reduced pulmonary functional capacity. It is therefore recommended that
Rouen, France; and ${ }^{\mathrm{i} D e p a r t m e n t ~ o f ~ R e s p i r a t o r y ~ a n d ~ E x e r c i s e ~ P h y s i o l o g y ~ a n d ~}$ CIC-CRB 1404, Rouen University Hospital, Rouen, France.

Received for publication June 27, 2018; revisions received Jan 9, 2019; accepted for publication Feb 3, 2019; available ahead of print April 11, 2019.

Address for reprints: Francis-Edouard Gravier, PT, Msc, ADIR Association, 147 avenue du Maréchal Juin, 76230 Bois-Guillaume, France (E-mail: kine@ adir-hautenormandie.com). $0022-5223 / \$ 36.00$

Copyright $\odot 2019$ by The American Association for Thoracic Surgery https://doi.org/10.1016/j.jtcvs.2019.02.016 


\begin{tabular}{|c|c|}
\hline \multicolumn{2}{|c|}{ Abbreviations and Acronyms } \\
\hline$\Delta$ & $\begin{aligned}= & \text { variation in value at first and } \\
& \text { second cardiopulmonary } \\
& \text { exercise testing }\end{aligned}$ \\
\hline AUC & $\begin{aligned}= & \text { area under the (receiver operating } \\
& \text { characteristic) curve }\end{aligned}$ \\
\hline COPD & $\begin{aligned}= & \text { chronic obstructive pulmonary } \\
& \text { disease }\end{aligned}$ \\
\hline CPET & $=$ cardiopulmonary exercise testing \\
\hline NAC & $=$ neoadjuvant chemotherapy \\
\hline NSCLC & $=$ non-small cell lung cancer \\
\hline ROC & $=$ receiver operating characteristic \\
\hline SD & $=$ standard deviation \\
\hline $\mathrm{VCO}_{2}$ & $=$ expired carbon dioxide flow \\
\hline VE & $=$ minute ventilation \\
\hline $\mathrm{VE} / \mathrm{VC}$ & $\begin{array}{l}=\text { linear regression of the ratio } \\
\text { between the increase in minute } \\
\text { ventilation and the expired } \\
\text { carbon dioxide flow }\end{array}$ \\
\hline $\mathrm{VO}_{2}$ & $=$ peak oxygen consumption \\
\hline
\end{tabular}

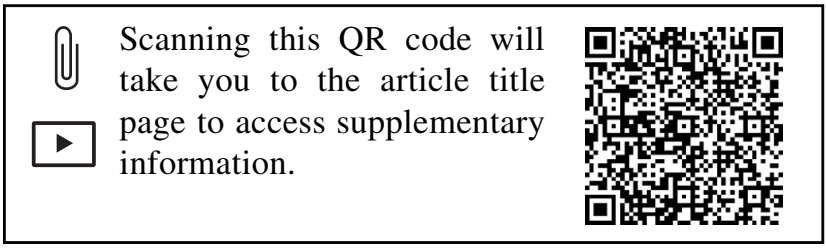

patients referred for resection undergo cardiopulmonary exercise testing (CPET) before the intervention to estimate the risks associated with surgery. Risk is determined according to the degree of limitation on functional tests (stair-climbing or shuttle test). ${ }^{2}$ The American Thoracic Society and the European Respiratory Society have determined that maximum oxygen consumption $\left(\mathrm{VO}_{2 \text { peak }}\right)$ thresholds of $<10$ and $>20 \mathrm{~mL} / \mathrm{kg} / \mathrm{min}$ respectively indicate patients are at "high" or "low" risk of complications; a value in between the two is considered to be a "moderate" risk. ${ }^{2,3}$ Two recent studies assessed ventilatory efficiency in patients with NSCLC who were eligible for surgery. They showed that the $\mathrm{VE} / \mathrm{VCO}_{2}$ slope, which is the linear regression of the ratio between the increase in minute ventilation (VE) and the expired carbon dioxide flow $\left(\mathrm{VCO}_{2}\right)$, was not only an accurate and independent predictive factor of mortality, but that it was also a more reliable predictor of postoperative complications than $\mathrm{VO}_{\text {2peak }} \cdot 4,5$

In the past few years, several studies have shown that preoperative physical exercise (termed prehabilitation) can optimize cardiorespiratory fitness measured according to $\mathrm{VO} 2_{\text {peak }}$ in patients with NSCLC before surgery. ${ }^{6-11}$
However, to our knowledge, no studies have specifically focused on the effect of prehabilitation on the $\mathrm{VE} / \mathrm{VCO}_{2}$ slope in these patients. The aim of this study was, therefore, to evaluate whether a prehabilitation program could improve ventilatory efficiency evaluated according to the $\mathrm{VE} / \mathrm{VCO}_{2}$ slope in patients awaiting lung resection surgery for NSCLC.

\section{METHODS \\ Study Design}

This retrospective cohort study was conducted on data collected between January 2014 and December 2017 in the Respiratory Physiology department of Rouen University Hospital in collaboration with ADIR Association (Aide à Domicile aux Insuffisants Respiratoires: Home care for chronic respiratory failure patients), an ambulatory pulmonary rehabilitation center. The study was approved by the Ethics Committee for Non-Interventional Research of Rouen University Hospital (CERNI E2018-17) (Video 1).

\section{Patients}

Data included in the analysis were from the records of patients aged at least 18 years old. They had all participated in a prehabilitation program before undergoing pulmonary resection for NSCLC and had undergone CPET before and after the prehabilitation. They were all considered at risk of postoperative complication because of a $\mathrm{VO}_{2 \text { peak }}<20 \mathrm{~mL} / \mathrm{kg} / \mathrm{min}$, associated with cardiorespiratory comorbidities, or receiving neoadjuvant chemotherapy (NAC).

\section{Data Extraction}

The characteristics of the population were extracted from the medical file. The following data were collected: age, sex, height, weight, body mass index, pulmonary function, exercise capacity before and after prehabilitation (CPET), smoking status (never/former/current), exposure to tobacco (expressed in pack/years; 1 pack/year $=1$ pack per day for 1 year), histology of the tumor and the stage according to the seventh Tumor, Node, Metastases classification. ${ }^{12}$

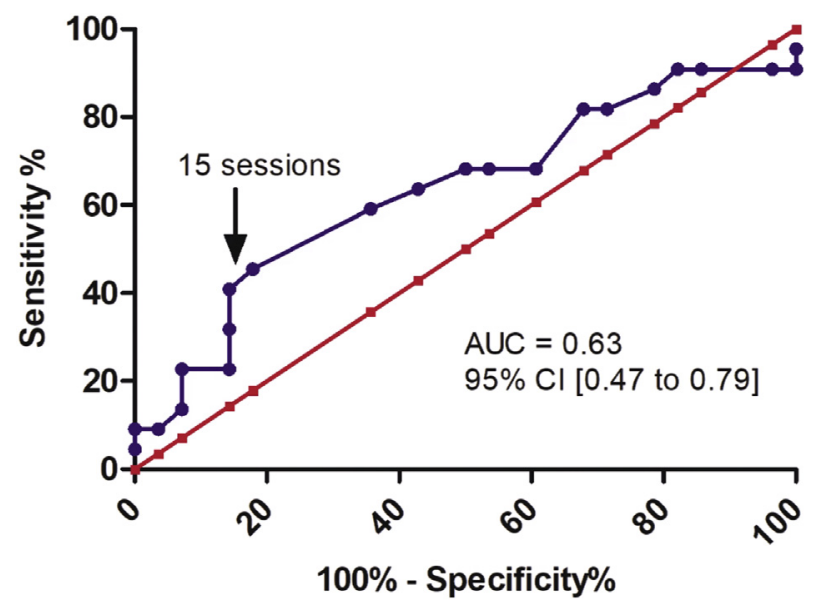

VIDEO 1. Summary of the study about the effect of ambulatory prehabilitation on ventilatory efficiency in non-small cell lung cancer patients: a cohort-study. Video available at: https://www.jtcvs.org/article/S00225223(19)30448-9/fulltext. 


\begin{abstract}
Assessments
CPET. CPET was performed using an electromagnetic ergometer (Ergoselect 200, Ergoline, Bitz, Germany) with a standardized, incremental protocol. After a 3-minute warm-up, incremental ramp exercise (5-20 W/ min) was maintained until exhaustion. A face mask (Hans Rudolph, Inc, Kansas City, Mo), pneumotach, and gas analyzer (Ergocard, Medisoft, Louvain, Belgium) were used to measure breath-by-breath oxygen consumption and carbon dioxide production $\left(\mathrm{VCO}_{2}\right)$. The end criteria for reaching maximal oxygen uptake were on the basis of American Thoracic Society/American College of Chest Physicians recommendations and ventilatory threshold was manually determined as the average of the results obtained using 4 methods: (1) first break in VE, (2) an increase in the VE/ oxygen consumption ratio with no change in the $\mathrm{VE} / \mathrm{VCO}_{2}$ ratio (Wasserman's method), (3) an increase in expired carbon dioxide, and (4) Beaver's method. ${ }^{13,14}$ Heart rates were continuously monitored with a 12-lead electrocardiogram (Ergocard).
\end{abstract}

Pulmonary function. Pulmonary function tests were carried out according to the American Thoracic Society and European Respiratory Society guidelines using plethysmography (Masterscreen, Jaeger, Wittsburg, Germany). Values were expressed as percentages of established theoretical values for European populations. ${ }^{15}$

\section{Prehabilitation Program}

The prehabilitation program was performed in an ambulatory setting at a frequency of 3 to 5 times a week, as a function of other medical appointments and additional examinations that were necessary in preparation for thoracic surgery. For patients who underwent preoperative NAC, rest days were also scheduled because of fatigue.

Each prehabilitation session lasted approximately 90 minutes and included:

- Endurance training (on a cycle ergometer or treadmill) at the ventilatory threshold, determined according to the initial CPET. The first session lasted for 15 to 20 minutes then increased by 5 minutes each session to reach 45 minutes in total (including a 5 -minute warm-up and 5 minutes of active recovery). The intensity was then increased by 5 or $10 \mathrm{~W}$, as could be tolerated;

- Peripheral muscle strengthening at $60 \%$ to $70 \%$ of the 1 -repetition maximum of 3 main components (quadriceps press, whole-leg extension, and upper limb pull down). Three sets of 12 movements were carried out for each exercise and the load was increased weekly as tolerated;

- Inspiratory muscle strengthening using a threshold valve (Threshold IMT, Respironics, Inc, Murrysville, PA) calibrated to at least $30 \%$ of the maximum inspiratory pressure if measured, or according to the patient's tolerance if data were lacking. Patients were encouraged to carry out 15 minutes of independent training daily and to increase the resistance regularly.

During the first session, patients were taught bronchial drainage techniques as well as directed coughing. Regular reminders were made during subsequent sessions to check that patients understood and were carrying out the techniques.

\section{Postoperative Data}

The postoperative length of stay, and the number of patients who developed at least 1 general complication, or at least 1 respiratory complication, were recorded. The severity of the most severe complication was graded according to the Clavien-Dindo classification. ${ }^{16}$

\section{Outcomes}

The primary outcome was change in the $\mathrm{VE} / \mathrm{VCO}_{2}$ slopes between the initial and final CPET at the end of the prehabilitation. Secondary outcomes were: (1) the proportion of patients with a $\mathrm{VE} / \mathrm{VCO}_{2}$ slope $>35$ before and after prehabilitation; this threshold was considered as the cutoff point for identifying increased risk of postoperative complications, (2) change in $\mathrm{VO}_{2 \text { peak }}$ before and after prehabilitation, (3) the relationship between changes in the $\mathrm{VE} / \mathrm{VCO}_{2}$ slope and $\mathrm{VO}_{2 \text { peak }}$, and (4) the number of training sessions needed to improve cardiorespiratory capacity.

\section{Statistical Analysis}

Continuous data are expressed as mean (standard deviation [SD]) or median (25th-75th percentile), as appropriate according to the distribution; normality was assessed using the Shapiro-Wilk test. Statistical comparative tests performed are specified in the legend of each table and adapted according to the paired or unpaired data and their distribution. The $\mathrm{McNe}-$ mar test was used to compare the proportion of patients with a $\mathrm{VE} / \mathrm{VCO}_{2}$ $>35$ before and after prehabilitation. The relationship between changes in the $\mathrm{VE} / \mathrm{VCO}_{2}$ slope and $\mathrm{VO}_{2 \text { peak }}$ was determined using a Spearman correlation test. A patient's response to prehabilitation was classified according to their having shown either an improvement of at least $8.1 \%$ (responder) or a change of less than $8.1 \%$ (nonresponder) in predicted $\mathrm{VO}_{2 \text { peak }}$ versus baseline tests, as recommended by Benzo and colleagues. ${ }^{17}$ The number of training sessions needed to obtain a physiological effect was estimated using sensitivity, specificity, and receiver operating characteristic (ROC) curve analyses. Because this study was exploratory, no correction for multiple testing was carried out. Prism 5.03 software (GraphPad Software, San Diego, Calif) was used for all analyses.

\section{RESULTS \\ Patients}

Among the 152 patients awaiting lung resection surgery for NSCLC assessed using CPET during the study period, 10 were excluded because either a diagnosis other than NSCLC was noted in their medical record or their CPET data were unusable. A further 78 patients did not participate in a prehabilitation program, another 14 did not undergo CPET at the end of the prehabilitation. Thus, physiological data from 50 patients were analyzed (Figure 1). Patient characteristics are presented in Table 1. Eleven patients did not undergo surgery after prehabilitation; surgical and postoperative data are presented in Table E1.

\section{$\mathrm{VE} / \mathrm{VCO}_{2}$ Slope}

In the complete cohort, $\mathrm{VE} / \mathrm{VCO}_{2}$ slope did not change significantly after the prehabilitation program (pre-prehabilitation: median, 37.1 [range, 33.8-43.4] vs postprehabilitation: median, 35.4 [range, 31.1-40.5]; $P=.09$, respectively; Table 2). A total of 26 patients $(52 \%)$ had a $\mathrm{VE} / \mathrm{VCO}_{2}$ slope $>35$ before prehabilitation, which remained unchanged after prehabilitation. Fourteen patients $(28 \%)$ had a $\mathrm{VE} / \mathrm{VCO}_{2}$ slope $<35$ before prehabilitation, which also remained unchanged. $\mathrm{VE} / \mathrm{VCO}_{2}$ slope decreased in 7 patients who began with a slope $<35$, and $\mathrm{VE} / \mathrm{VCO}_{2}$ slope increased in 3 patients with initial slopes $>35$. There was no difference in the proportion of patients with a VE/ $\mathrm{VCO}_{2}$ slope $<35$ before and after prehabilitation $(P=.34)$.

\section{$V_{O_{2 p e a k}}$, and Other CPET Data}

In the complete cohort, $\mathrm{VO}_{2 \text { peak }}$ increased significantly between the initial and final CPETs (median, 13.2 [range, 


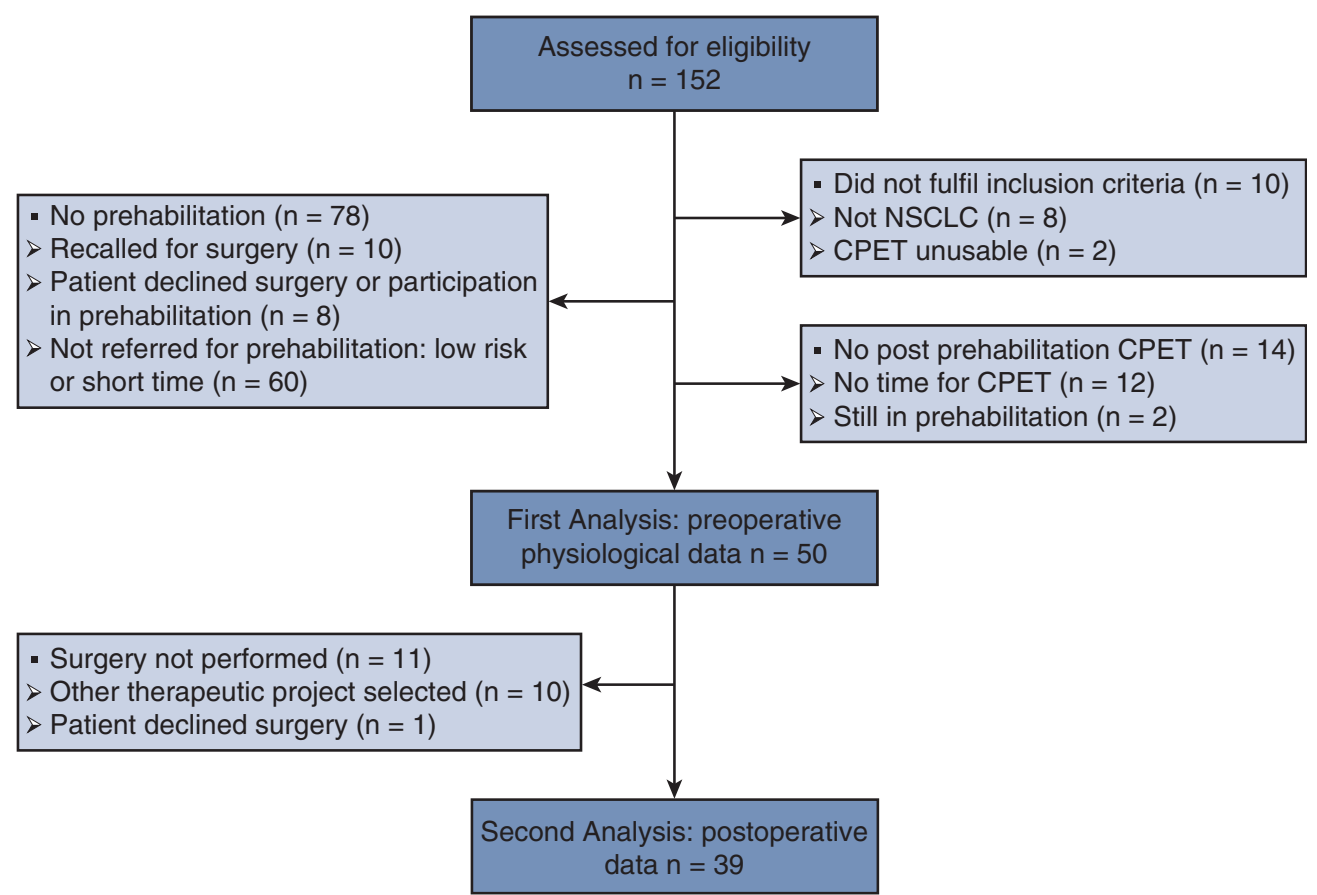

FIGURE 1. Flow chart of the inclusion of patient records for analysis from January 2014 to December 2017. NSCLC, Non-small cell lung cancer; CPET, cardiopulmonary exercise testing.

11.9-14.7] vs median, 14.8 [range, $13.1-16.4] \mathrm{mL} / \mathrm{kg} / \mathrm{min}$; $P<.01$, respectively). Maximum power reached also increased significantly between the initial and final CPETs (mean, 73.16 [SD, 21.64] vs mean, 82.76 [SD, 23.98] W; $P<.01$, respectively). Comparisons of all CPET results before and after prehabilitation are shown in Table 2.

\section{Correlation between Change in $\mathrm{VE} / \mathrm{VCO}_{2}$ Slope and $\mathrm{VO}_{\text {2peak }}$}

The relationship between changes in the $\mathrm{VE} / \mathrm{VCO}_{2}$ slope and $\mathrm{VO}_{2 \text { peak }}$ was evaluated. There was a significant moderate negative correlation between $\triangle \mathrm{VE} / \mathrm{VCO}_{2}$ slope and $\Delta \mathrm{VO}_{2 \text { peak }}(r=-0.38 ; P<.01 ;$ Figure 2$)$.

\section{Number of Training Sessions}

The median number of sessions was 16 (range, 13-21), with a median training time of 6 (range, 4-8) weeks and a mean frequency of 3.1 (SD, 1.3) sessions per week. The prehabilitation program was always adapted to the patient's surgery schedule and surgery was never delayed.

Of the 50 patients included in the analysis, 28 had improvements in $\mathrm{VO}_{2 \text { peak }}$ above $8.1 \%$ and were considered as responders to the prehabilitation program. It was not possible to accurately determine a threshold number of sessions using the ROC curve analysis because the validity of the area under the (ROC) curve (AUC) as well as sensitivity and specificity values were poor (AUC, 0.63 [95\% confidence interval, 0.47-0.79]; Figure 3). Therefore, on the basis of visual analysis of the ROC curve and our clinical experience, we hypothesized that at least 15 sessions of prehabilitation might be necessary to obtain a clinical response.

To test this hypothesis, a subgroup analysis of $\mathrm{VE} / \mathrm{VCO}_{2}$ slope and $\mathrm{VO}_{2 \text { peak }}$ was undertaken in patients who trained for at least 15 sessions compared with those who underwent fewer than 15 sessions of prehabilitation. The results indicated significant physiological improvements in those who carried out at least 15 sessions (Table 3). Analysis of postoperative data did not show any significant difference in postoperative length of stay, the number of patients who developed at least 1 general or respiratory complication, and the severity of these complications (Table E2).

\section{Cancer Stage, NAC, and Response to Prehabilitation}

The present distribution of stage is not in keeping with the usual surgical practice. Indeed, some patients have benefited from surgery following a preoperative multidisciplinary assessment and the use of a NAC. A complementary analysis of the patients considered at early stage without NAC versus those with a more severe stage and/or requiring NAC is reported separately in Table 4. Patients considered to be more severe in oncological status seemed to have a less impaired baseline respiratory function with, however, an equivalent cardiorespiratory level. The response to training in terms of $\mathrm{VE} / \mathrm{VCO}_{2}$ slope or $\mathrm{VO}_{2 \text { peak }}$ was not significantly different. 
TABLE 1. Patient characteristics $(n=50)$

\begin{tabular}{|c|c|}
\hline Variable & Value \\
\hline Female sex* & $11(22.0)$ \\
\hline Age, $y \dagger$ & $63.4(6.6)$ \\
\hline $\mathrm{BMI} \dagger$ & $26.3(5.7)$ \\
\hline FEV1, \% th. $\dagger$ & $62.0(19.0)$ \\
\hline FEV1/FVC $<0.7^{*}$ & $38(76.0)$ \\
\hline $\mathrm{RV} / \mathrm{TLC} \dagger$ & $52.5(10.7)$ \\
\hline \multicolumn{2}{|l|}{ Tobacco use } \\
\hline Smoker* & $20(40.0)$ \\
\hline Former* & $30(60.0)$ \\
\hline Exposure, pack-years $\dagger$ & $52.9(20.0)$ \\
\hline DLCO, $\%$ th. $\dagger$ & $54.7(17.0)$ \\
\hline $\mathrm{VO}_{2 \text { peak }}, \mathrm{mL} / \mathrm{kg} / \mathrm{min} \ddagger$ & $13.2(11.9-14.7)$ \\
\hline VE/ $/ \mathrm{VCO}_{2}$ slope $\ddagger$ & $37.1(33.8-43.4)$ \\
\hline \multicolumn{2}{|l|}{ NSCLC stage* } \\
\hline 0 & $1(2.0)$ \\
\hline Ia & $9(18.0)$ \\
\hline $\mathrm{Ib}$ & $5(10.0)$ \\
\hline IIa & $4(8.0)$ \\
\hline $\mathrm{IIb}$ & $2(4.0)$ \\
\hline IIIa & $7(14.0)$ \\
\hline IIIb & $6(12.0)$ \\
\hline IV & $7(14.0)$ \\
\hline NS & $9(18.0)$ \\
\hline \multicolumn{2}{|l|}{ Histology* } \\
\hline Large-cell carcinoma & $8(16.0)$ \\
\hline Squamous carcinoma & $15(30.0)$ \\
\hline Adenocarcinoma & $18(36.0)$ \\
\hline NS & $9(18.0)$ \\
\hline
\end{tabular}

$B M I$, Body mass index; $F E V I$, forced expiratory volume in 1 second; $\%$ th., $\%$ of theoretical value; $F V C$, forced vital capacity; $R V$, residual volume; $T L C$, total lung capacity; $D L C O$, diffusing capacity of the lung for carbon monoxide; $V O_{2 p e a k}$, peak of oxygen consumption; $V E$, minute ventilation; $V C O 2$, expired carbon dioxide flow; $V E / V C O_{2}$ slope, linear regression of the ratio between the increase in minute ventilation and the expired carbon dioxide flow; $N S C L C$, non-small-cell lung cancer; $N S$, not specified. *Values expressed as $\mathrm{n}(\%)$. $\dagger$ Values expressed as mean (standard deviation). $\ddagger$ Values expressed as median (25th-75th percentile).

\section{DISCUSSION}

The results of this study showed that ventilatory efficiency, as evaluated according to the $\mathrm{VE} / \mathrm{VCO}_{2}$ slope did not change after a prehabilitation program in 50 patients awaiting lung resection surgery for NSCLC. In contrast, the $\mathrm{VE} / \mathrm{VCO}_{2}$ slopes of a subsample of these patients, who trained for more than 15 sessions, did improve significantly, however this result was not clinically relevant because the coefficient remained $>35$. Furthermore, the $\triangle \mathrm{VE} / \mathrm{VCO}_{2}$ slope was not significantly different between the subgroups, suggesting that there was no change in the level of postoperative risk of complications on the basis of these criteria. ${ }^{4}$ The proportion of patients with VE/ $\mathrm{VCO}_{2}$ slopes $<35$ did not change from the beginning to the end of the prehabilitation program.
To our knowledge, this is the first study to evaluate the effect of prehabilitation before lung resection for NSCLC on $\mathrm{VE} / \mathrm{VCO}_{2}$ slope. Very few data for $\mathrm{VE} / \mathrm{VCO}_{2}$ slope in patients with NSCLC are available in the literature. Only 3 studies have reported this parameter, but they did not discuss its relevance. Bobbio and colleagues ${ }^{7}$ reported a significant change in $\mathrm{VE} / \mathrm{VCO}_{2}$ slope in 12 patients (mean 38 $[\mathrm{SD}, 7]$ vs mean $35[\mathrm{SD}, 6] ; P=.001)$ after an intensive 5 -session per week prehabilitation program over 4 weeks. Conversely, however, Divisi and colleagues ${ }^{10}$ reported no significant changes in $\mathrm{VE} / \mathrm{VCO}_{2}$ slope (mean, 33 [SD, 11] vs mean, 29 [SD, 6]; $P=.13$ ) in 27 patients with chronic obstructive pulmonary disease (COPD), despite an intensive prehabilitation program (6 sessions per week for 4 weeks). More recently, Licker and colleagues ${ }^{11}$ reported no difference in $\triangle \mathrm{VE} / \mathrm{VCO}_{2}$ slope in patients who participated in prehabilitation including high-intensity interval training 3 times per week for 3 weeks compared with those who received usual care $(\mathrm{n}=136$; median, -0.6 [range, -4.8 to 4.2 ] vs median, -0.7 [range, -5.9 to 5.2 ], respectively; $P=.73$ ).

Despite the lack of improvement in $\mathrm{VE} / \mathrm{VCO}_{2}$ slope, $\mathrm{VO}_{2 \text { peak }}$ and maximum power reached improved markedly, as has been previously shown. A significant but moderate correlation was found between $\triangle \mathrm{VE} / \mathrm{VCO}_{2}$ slope and $\Delta \mathrm{VO}_{2 \text { peak }}(r=-0.38 ; P<.01)$, suggesting that ventilatory efficiency did contribute to improving $\mathrm{VO}_{2 \text { peak }}$, but only slightly.

Ventilatory efficiency during exercise is increasingly reported as a key indicator of severity and prognosis in patients with $\mathrm{COPD}^{18}$ and chronic heart failure. In the present cohort of patients with NSCLC, $76 \%$ also had COPD and a history of high level of exposure to tobacco. The VE/ $/ \mathrm{VCO}_{2}$ slope is known to be increased in patients with moderate COPD, especially those with hyperinflation, ${ }^{19}$ which was the case for many patients in the present cohort (Table 1). The large reduction in diffusing capacity of the lung for carbon monoxide in this cohort suggests that other structural determinants of ventilatory inefficiency (emphysema, ventilation-perfusion mismatching, and microvascular disease) contributed to the observed lack of change in the $\mathrm{VE} / \mathrm{VCO}_{2}$ slope. ${ }^{18,19} \mathrm{~A}$ high $\mathrm{VE} / \mathrm{VCO}_{2}$ slope is known to be associated with a risk of pulmonary arterial hypertension in patients with $\mathrm{COPD},{ }^{20}$ and has been suggested as a possible indicator of subclinical heart failure in patients referred for pneumonectomy. ${ }^{21}$

The VE/ $/ \mathrm{VCO}_{2}$ slope is more commonly evaluated in patients with chronic heart failure. Two recent meta-analyses on the effects of exercise training in patients with heart failure also notably failed to show any benefits of exercise training on the $\mathrm{VE} / \mathrm{VCO}_{2}$ slope, even with high-intensity interval training. ${ }^{22,23}$

It would therefore appear that prehabilitation has little effect on ventilatory inefficiency found during CPET in 
TABLE 2. Cardiopulmonary exercise testing results before and after prehabilitation

\begin{tabular}{|c|c|c|c|c|}
\hline Variable & $\mathbf{n}$ & Before prehabilitation & After prehabilitation & $P$ value \\
\hline $\mathrm{VE} / \mathrm{VCO}_{2}$ slope* & 50 & $37.1(33.8-43.4)$ & $35.4(31.1-40.5)$ & .09 \\
\hline $\mathrm{VO}_{2 \text { peak }}, \mathrm{mL} / \mathrm{kg} / \mathrm{min} *$ & 50 & $13.2(11.9-14.7)$ & $14.8(13.1-16.4)$ & $<.01 \dagger$ \\
\hline $\mathrm{VO}_{2 \text { peak }}, \%$ th. $\ddagger$ & 50 & $58.18(10.05)$ & $63.84(10.31)$ & $<.01 \dagger$ \\
\hline $\mathrm{W}_{\text {peak }}, \mathrm{W}_{\ddagger}^{\dagger}$ & 49 & 73.16 (21.64) & $82.76(23.98)$ & $<.01 \dagger$ \\
\hline $\mathrm{W}_{\text {peak }}, \%$ th. $\ddagger$ & 49 & $56.65(12.92)$ & $63.84(10.31)$ & $<.01 \dagger$ \\
\hline $\mathrm{W}_{\mathrm{VT}}, \mathrm{W}^{*}$ & 47 & $40(30-50)$ & $45(40-60)$ & $<.01 \dagger$ \\
\hline $\mathrm{VO}_{2 \mathrm{VT}} / \mathrm{VO}_{2 \text { peak }}, \% *$ & 47 & $43(35-48)$ & $44(38-49)$ & $.04 \dagger$ \\
\hline
\end{tabular}

$\mathrm{VE}$, Minute ventilation; $\mathrm{VCO}_{2}$, expired carbon dioxide flow; $\mathrm{VE} / \mathrm{VCO}_{2}$ slope, linear regression of the ratio between the increase in minute ventilation and the expired carbon dioxide flow; $V O_{2 p e a k}$, peak of oxygen consumption; \% th., \% of theoretical value; $W_{\text {peak }}$, maximum power reached; $V O_{2 V T}$, oxygen consumption at ventilatory threshold; $V O_{2 V T} / V O_{2 p e a k}$, ratio of the oxygen consumption at ventilatory threshold and theoretical peak of oxygen consumption. *Values expressed as median (25th-75th percentile). $\dagger P<.05$; Wilcoxon matched pair signed rank test or a paired $t$ test according to distributions. $\ddagger$ Values expressed as mean (standard deviation).

patients awaiting lung resection for NSCLC. Medical teams should therefore consider other outcomes to evaluate the success of prehabilitation programs, keeping in mind the risks involved for patients with a high $\mathrm{VE} / \mathrm{VCO}_{2}$ slope, even with an acceptable $\mathrm{VO}_{2 \text { peak }}$.

To our knowledge, this is the first study to have attempted to determine the minimum dose-response of ambulatory prehabilitation sessions in patients with NSCLC. Unfortunately, because of the retrospective design of the study, the methodology was limited regarding the measurement of this criterion. Also, the AUC of the ROC curve on the basis of responders and nonresponders to prehabilitation was uninterpretable (AUC, 0.63 [95\% confidence interval, 0.47-0.79]; Figure 2).

We therefore compared patients who had completed at least 15 training sessions or fewer than 15 training sessions. This number was on the basis of our clinical experience and the fact it is realistic in clinical practice and can be adjusted to the oncological context, in which prehabilitation must be

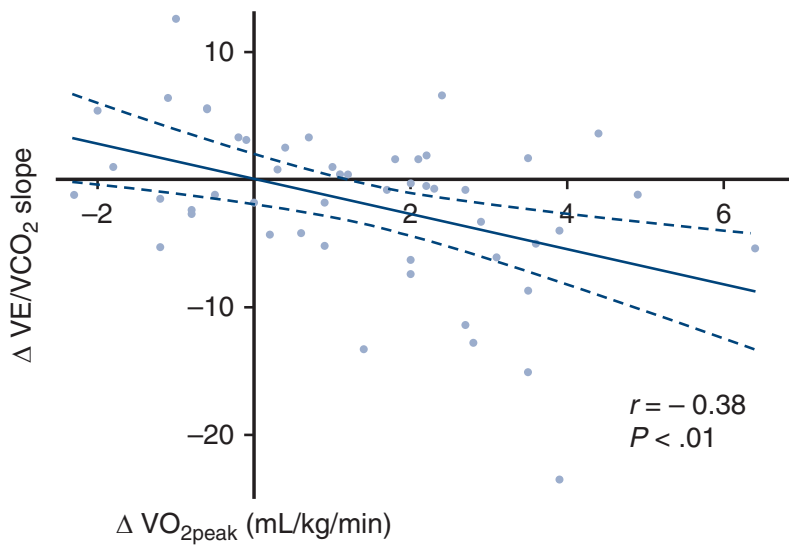

FIGURE 2. Correlation between the change $(\Delta)$ in the ventilator efficiency measured by the linear regression of the ratio between the increase in minute ventilation $(\mathrm{VE})$ and the expired carbon dioxide flow $\left(\mathrm{VCO}_{2}\right)$ called $\mathrm{VE} / \mathrm{VCO}_{2}$ slope and the peak of oxygen consumption $\left(\mathrm{VO}_{2 p e a k}\right)$ after the prehabilitation program. rapid. This subgroup analysis showed that there was no improvement in either $\mathrm{VO}_{2 \text { peak }}$ or $\mathrm{VE} / \mathrm{VCO}_{2}$ slope for the group of patients who trained for fewer than 15 sessions in this ambulatory program of approximately 6 weeks' duration, whereas these parameters improved significantly for those who underwent at least 15 sessions. As already stated, $\mathrm{VO}_{2 \text { peak }}$ seems to be a more sensitive outcome to evaluate the effectiveness of prehabilitation. The results suggest that patients should undergo at least 15 sessions of prehabilitation for an effect to occur. However, the number of patients who developed a postoperative general or respiratory complication and the severity of these complications did not differ significantly between those who underwent fewer than or at least 15 sessions (Table E2). Clinically, the difference in the complication rate appears substantial, especially for respiratory complications

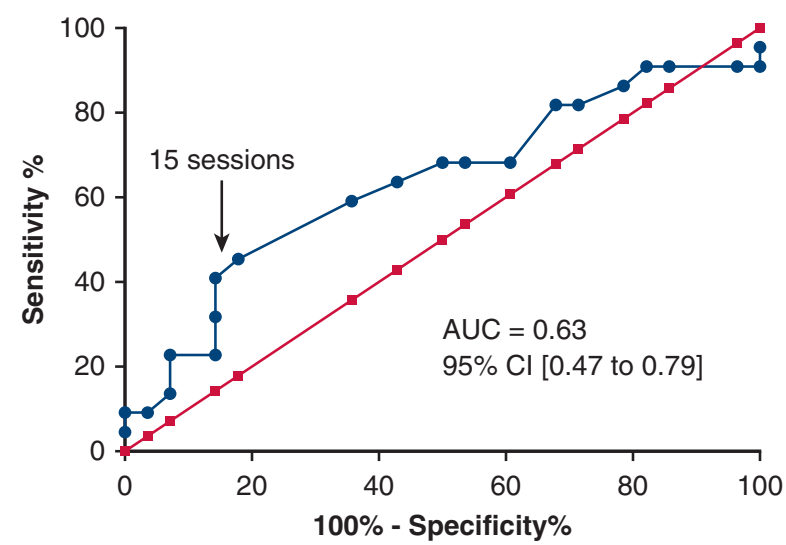

FIGURE 3. The receiver operating characteristic curve (ROC curve) performed to determine a threshold of training sessions needed to obtain a physiological response: sensitivity (percent of responders to prehabilitation) is plotted against $100 \%$ specificity percent (percent of nonresponders to prehabilitation) at each possible threshold. Accuracy is measured by the area under the curve $(A U C)$. An area of $1=$ perfect; an area of $0.5=$ inadequate. $C I$, Confidence interval. 
TABLE 3. Analysis of the $\mathrm{VE} / \mathrm{VCO}_{2}$ slope and $\mathrm{VO}_{2 \text { peak }}$ before and after the prehabilitation program for patients who trained for fewer than or $\geq 15$ sessions

\begin{tabular}{|c|c|c|c|}
\hline Variable & Before prehabilitation & After prehabilitation & $P$ value \\
\hline \multicolumn{4}{|l|}{$\mathrm{VE} / \mathrm{VCO}_{2}$ slope } \\
\hline$<15$ sessions $(\mathrm{n}=15)^{*}$ & $36.5(31.9-43.8)$ & $35.4(31.4-42.4)$ & .82 \\
\hline$\geq 15$ sessions $(\mathrm{n}=35)^{*}$ & $37.4(33.8-43.2)$ & $35.1(30.4-40.4)$ & $.02 \dagger$ \\
\hline$\Delta \mathrm{VE} / \mathrm{VCO}_{2}$ slope $<15$ vs $\geq 15$ sessions* & \multicolumn{2}{|c|}{$-0.5(-1.8$ to 5.4$)$ vs $-1.2(-5.4$ to 1.7$)$} & .10 \\
\hline \multicolumn{4}{|l|}{$\mathrm{VO}_{2 \text { peak }}, \mathrm{mL} / \mathrm{kg} / \mathrm{min}$} \\
\hline$<15$ sessions $(\mathrm{n}=15) \ddagger$ & $14.3(2.6)$ & $14.4(2.9)$ & .77 \\
\hline$\geq 15$ sessions $(\mathrm{n}=35)^{*}$ & $12.6(11.9-14.6)$ & $15.0(13.5-16.7)$ & $<.01 \dagger$ \\
\hline$\Delta \mathrm{VO}_{2 \text { peak }}<15$ vs $\geq 15$ sessions $\ddagger$ & \multicolumn{2}{|c|}{$0.11(1.4)$ vs $1.9(1.9)$} & $<.01 \dagger$ \\
\hline
\end{tabular}

$V E$, Minute ventilation; $\mathrm{VCO}_{2}$, expired carbon dioxide flow; $\mathrm{VE} / \mathrm{VCO}_{2}$ slope, linear regression of the ratio between the increase in minute ventilation and the expired carbon dioxide flow; $\Delta$, variation between value at first and second cardiopulmonary exercise testing session; $V O_{2 \text { peak }}$, peak of oxygen consumption. *Values expressed as median (25th-75th percentile). $\dagger P<.05$; Wilcoxon matched pair signed rank test or a paired $t$ test according to distributions for intragroup analysis; Mann Whitney test or unpaired $t$ test according to distributions for intergroup analysis. $\ddagger$ Values expressed as mean (standard deviation).

$(58.3 \%$ vs $37 \%)$, however, the statistical power of the cohort was likely too low to reach significance.

It must be noted that the population of this cohort is not in keeping with the usual surgical practice. Indeed, this cohort concentrates only those for whom it was considered essential for them to undergo prehabilitation in a context of postoperative risks. In the present cohort, 6 patients with NSCLC stage IIIB and 7 with stage IV participated in a prehabilitation program before lung resection. A surgical project was suggested after careful multidisciplinary evaluation and were under closely supervised NAC for some of them ${ }^{24,25}$ A total of 13 patients underwent chemotherapy at the same time as prehabilitation. This generally involved a combination of carboplatin and pemetrexed, usually administered at intervals of 3 weeks. The median number of treatment cycles was 3 , most of which started before the prehabilitation program. In agreement with previous study, exercise re-training was feasible and without adverse events related to physical activity in patients receiving NAC. ${ }^{26}$

NAC presents adverse effects on pulmonary function and especially diffusion capacity ${ }^{27,28}$ as well as the toxic effects

TABLE 4. Subgroup analysis for patients with early cancer stage ( $\leq$ IIIa) without NAC versus late stage ( $\geq$ IIIb) and/or with NAC

\begin{tabular}{|c|c|c|c|}
\hline Variable & Stage $\leq$ IIIa/no NAC $(n=33)$ & Stage $\geq$ IIIb/NAC $(n=17)$ & $P$ value \\
\hline \multicolumn{4}{|l|}{ Characteristics before prehabilitation } \\
\hline Age, $\mathrm{y}^{*}$ & $63.7(7.1)$ & $62.7(5.4)$ & .59 \\
\hline FEV1, L* & $1.8(0.6)$ & $2.0(0.6)$ & .10 \\
\hline FEV1, \% th. $\dagger$ & $57.0(45.0-69.5)$ & $68.0(52.5-80.5)$ & .11 \\
\hline $\mathrm{FVC}, \mathrm{L} \dagger$ & $3.0(2.3-3.2)$ & $3.3(2.6-4.1)$ & .06 \\
\hline FVC, $\%$ th. $\dagger$ & $78.0(72.0-88.5)$ & $88(79.0-102.5)$ & .06 \\
\hline DLCO, $\%$ th.* & $52.4(18.6)$ & $58.9(12.8)$ & .21 \\
\hline $\mathrm{RV} / \mathrm{TLC}^{\dagger}$ & $57.6(50.1-61.8)$ & $45.6(38.7-55.1)$ & $<.01 \ddagger$ \\
\hline $\mathrm{VO}_{2 \text { peak }}, \mathrm{mL} / \mathrm{kg} / \mathrm{min} \dagger$ & $13.0(11.8-14.6)$ & $13.4(12.1-15.7)$ & .44 \\
\hline $\mathrm{VO}_{2 \text { peak }}, \%$ th.* & $59.3(11.0)$ & $56.0(7.7)$ & .26 \\
\hline $\mathrm{VE} / \mathrm{VCO}_{2}$ slope $\dagger$ & $36.5(33.6-43.9)$ & $37.8(35.1-43.0)$ & .44 \\
\hline \multicolumn{4}{|l|}{ Response to prehabilitation } \\
\hline Number of sessions* & $16.3(6.1)$ & $18.4(6.2)$ & .26 \\
\hline \multicolumn{4}{|l|}{$\Delta \mathrm{VO}_{2 \text { peak }}, \mathrm{mL} / \mathrm{kg} / \mathrm{min}$} \\
\hline All* & $1.4(2.0)$ & $1.3(1.9)$ & .98 \\
\hline$<15$ sessions $(\mathrm{n}=10$ and 5$) \dagger$ & $-0.2(-1.1$ to 1.8$)$ & $0.0(-1.3$ to 1.5$)$ & 1.00 \\
\hline$\geq 15$ sessions $(\mathrm{n}=23 \text { and } 12)^{*}$ & $1.9(2.0)$ & $1.9(1.8)$ & .97 \\
\hline \multicolumn{4}{|l|}{$\Delta \mathrm{VE} / \mathrm{VCO}_{2}$ slope $\dagger$} \\
\hline $\mathrm{All} \dagger$ & $-1.2(-5.4$ to 1.0$)$ & $-0.3(-2.3$ to 4.4$)$ & .16 \\
\hline$<15$ sessions $(\mathrm{n}=10$ and 5$) \dagger$ & $-0.7(-1.7$ to 2.2$)$ & $1.6(-1.8$ to 5.5$)$ & .76 \\
\hline$\geq 15$ sessions $(\mathrm{n}=23$ and 12$)$ & $-4.0(-6.1$ to 1.0$)$ & $-0.6(-3.9$ to 2.9$)$ & .22 \\
\hline
\end{tabular}

$N A C$, Neoadjuvant chemotherapy; $F E V I$, forced expiratory volume in 1 second; $F V C$, forced vital capacity; $D L C O$, diffusing capacity of the lung for carbon monoxide; $R V$, residual volume; $T L C$, total lung capacity; $V O_{2 p e a k}$, peak of oxygen consumption; $\%$ th., \% of theoretical value; $V E$, minute ventilation; $V C \mathrm{O}_{2}$, expired carbon dioxide flow; $V E / V C O_{2}$ slope, linear regression of the ratio between the increase in minute ventilation and the expired carbon dioxide flow. *Values expressed as mean (standard deviation). $\dagger$ Values expressed as median (25th-75th percentile). $\ddagger P<.05$; Mann-Whitney test or unpaired $t$ test according to distributions. 
on heart and muscle mitochondrial activity. ${ }^{29}$ Secondary analyses according to stage of cancer or NAC did not show significant differences. However, it is interesting to note that the subgroup of 23 early stage patients who performed at least 15 sessions and who did not receive NAC, still decreased their $\mathrm{VE} / \mathrm{VCO}_{2}$ slope by 4 points (Table 4 ).

This study has several limitations. First, there might be some bias because of the retrospective design. However, all of the assessments were standardized according to current guidelines, and we provided data from 50 patients with NSCLC before and after prehabilitation. Unfortunately, the population was quite heterogeneous and secondary analyses according to the number of sessions or the severity of the patients reduced statistical power. This study also reflects current prehabilitation practice, because it involved patients in an ambulatory pulmonary rehabilitation center. Most rehabilitation studies included in previous meta-analyses were based in a hospital setting, ${ }^{30,31}$ despite the fact that very few hospitals routinely offer prehabilitation as a treatment except as part of clinical studies.

Other assessments of ventilatory function might have complemented the CPET. Prehabilitation has been shown to improve forced expiratory volume in 1 second and forced vital capacity ${ }^{31}$ and it would be interesting to determine if these latter resting parameters correlate with ventilatory efficiency during exercise.

This cohort study was noncontrolled. In a recent study that involved the same prehabilitation program as the present work, Boujibar and colleagues ${ }^{32}$ showed that patients who underwent prehabilitation had fewer and less severe complications than those who did not undergo prehabilitation, despite the fact $\mathrm{VO}_{2 \text { peak }}$ was similar between both groups. In that study the patients underwent a median number of 17 (range, 14-20) sessions. The number of patients without complications or whose condition resolved with medical treatment (no surgical or unplanned intensive care), corresponding to a Clavien-Dindo classification $\leq 2$, was 17 of 19 in the prehabilitation group, and 8 of 15 in the non-prehabilitation group $(P=.0252)$. Despite the significant reduction in the rate and severity of complications in the prehabilitation group, the number of sessions needed to achieve this effect could not be determined.

Finally, with regard to our proposal that a minimum of 15 sessions should be carried out to obtain benefits from the training should be interpreted with caution because it is on the basis of only a clinical assumption and does not take into account the intensity of the training. Licker and colleagues ${ }^{11}$ showed that CPET parameters and the rate of postoperative complications could be improved with a short 2 -week in-hospital program (median, 8 sessions). Thus the threshold of 15 sessions might only apply to longer-term ambulatory programs such as the one presented herein. Prehabilitation protocols are currently very heterogeneous, ranging from 3 to 6 weeks of training at a rate of 3 to 6 times per week, with intensities of $50 \%$ to $80 \%$ of maximum power. Moreover, different training techniques such as continuous, interval, or incremental training are used. Preoperative training programs might also include one or a combination of different adjuvants such as educational support, chest physiotherapy, nutritional supplementation, etc. $^{30,31}$ Future studies should aim to produce standardized programs, on the basis of the optimal dose.

\section{CONCLUSIONS}

Ventilatory efficiency measured according to the VE/ $\mathrm{VCO}_{2}$ slope is a powerful predictor of postoperative complications in patients with NSCLC after lung resection surgery. However, despite the beneficial effects of prehabilitation on other cardiorespiratory parameters, prehabilitation did not change ventilatory efficiency. Fifteen sessions of prehabilitation or more seems to be a rational threshold to improve other CPET outcomes, while remaining applicable in clinical practice. Prospective data are needed to confirm these observations.

\section{Conflict of Interest Statement}

Authors have nothing to disclose with regard to commercial support.

We thank the Aide à Domicile aux Insuffisants Respiratoires Association for supporting this work; Alain Boutry and Gwenaëlle Leteurtre for their support during data collection; and Johanna Robertson for revision of the English.

\section{References}

1. Howington JA, Blum MG, Chang AC, Balekian AA, Murthy SC. Treatment of stage I and II non-small cell lung cancer: diagnosis and management of lung cancer, 3rd ed: American College of Chest Physicians evidence-based clinical practice guidelines. Chest. 2013;143(5 suppl):e278S-313S.

2. Brunelli A, Kim AW, Berger KI, Addrizzo-Harris DJ. Physiologic evaluation of the patient with lung cancer being considered for resectional surgery: diagnosis and management of lung cancer, 3rd ed: American College of Chest Physicians evidence-based clinical practice guidelines. Chest. 2013;143(5 suppl): e166S-90S.

3. Brunelli A, Charloux A, Bolliger CT, Rocco G, Sculier JP, Varela G, et al. ERS/ ESTS clinical guidelines on fitness for radical therapy in lung cancer patients (surgery and chemo-radiotherapy). Eur Respir J. 2009;34:17-41.

4. Torchio R, Guglielmo M, Giardino R, Ardissone F, Ciacco C, Gulotta C, et al Exercise ventilatory inefficiency and mortality in patients with chronic obstructive pulmonary disease undergoing surgery for non-small-cell lung cancer. Eur J Cardiothorac Surg. 2010;38:14-9.

5. Brunelli A, Belardinelli R, Pompili C, Xiume F, Refai M, Salati M, et al. Minute ventilation-to-carbon dioxide output (VE/VCO2) slope is the strongest predictor of respiratory complications and death after pulmonary resection. Ann Thorac Surg. 2012;93:1802-6.

6. Jones LW, Peddle CJ, Eves ND, Haykowsky MJ, Courneya KS, Mackey JR, et al Effects of presurgical exercise training on cardiorespiratory fitness among patients undergoing thoracic surgery for malignant lung lesions. Cancer. 2007 110:590-8.

7. Bobbio A, Chetta A, Ampollini L, Primomo GL, Internullo E, Carbognani P, et al. Preoperative pulmonary rehabilitation in patients undergoing lung resection for non-small cell lung cancer. Eur J Cardiothorac Surg. 2008;33:95-8.

8. Stefanelli F, Meoli I, Cobuccio R, Curcio C, Amore D, Casazza D, et al. Highintensity training and cardiopulmonary exercise testing in patients with chronic 
obstructive pulmonary disease and non-small-cell lung cancer undergoing lobectomy. Eur J Cardiothorac Surg. 2013;44:e260-5.

9. Coats V, Maltais F, Simard S, Frechette E, Tremblay L, Ribeiro F, et al. Feasibility and effectiveness of a home-based exercise training program before lung resection surgery. Can Respir J. 2013;20:e10-6.

10. Divisi D, Di Francesco C, Di Leonardo G, Crisci R. Preoperative pulmonary rehabilitation in patients with lung cancer and chronic obstructive pulmonary disease. Eur J Cardiothorac Surg. 2013;43:293-6.

11. Licker M, Karenovics W, Diaper J, Fresard I, Triponez F, Ellenberger C, et al. Short-term preoperative high-intensity interval training in patients awaiting lung cancer surgery: a randomized controlled trial. J Thorac Oncol. 2017;12: 323-33.

12. Bergman P, Brodin D, Lewensohn R, de Petris L. Validation of the 7th TNM classification for non-small cell lung cancer: a retrospective analysis on prognostic implications for operated node-negative cases. Acta Oncol. 2013;52:1189-94.

13. Beaver WL, Wasserman K, Whipp BJ. A new method for detecting anaerobic threshold by gas exchange. J Appl Physiol (1985). 1986;60:2020-7.

14. ATS/ACCP Statement on cardiopulmonary exercise testing. Am J Respir Crit Care Med. 2003;167:211-77.

15. Quanjer PH, Tammeling GJ, Cotes JE, Pedersen OF, Peslin R, Yernault JC. Lung volumes and forced ventilatory flows. Report working party standardization of lung function tests, European community for steel and coal. Official statement of the European Respiratory Society. Eur Respir J Suppl. 1993;16:5-40.

16. Dindo D, Demartines N, Clavien PA. Classification of surgical complications: a new proposal with evaluation in a cohort of 6336 patients and results of a survey. Ann Surg. 2004;240:205-13.

17. Benzo R, Kelley GA, Recchi L, Hofman A, Sciurba F. Complications of lung resection and exercise capacity: a meta-analysis. Respir Med. 2007; 101:1790-7.

18. Neder JA, Berton DC, Arbex FF, Alencar MC, Rocha A, Sperandio PA, et al. Physiological and clinical relevance of exercise ventilatory efficiency in COPD. Eur Respir J. 2017;49:1602036.

19. Neder JA, Berton DC, Muller PT, Elbehairy AF, Rocha A, Palange P, et al. Ventilatory inefficiency and exertional dyspnea in early chronic obstructive pulmonary disease. Ann Am Thorac Soc. 2017;14(suppl 1):S22-9.

20. Holverda S, Bogaard HJ, Groepenhoff H, Postmus PE, Boonstra A, VonkNoordegraaf A. Cardiopulmonary exercise test characteristics in patients with chronic obstructive pulmonary disease and associated pulmonary hypertension. Respiration. 2008;76:160-7.

21. Torchio R, Mazzucco A, Guglielmo M, Giardino R, Ciacco C, Ardissone F. Minute ventilation to carbon dioxide output (V'E/V'CO2 slope) is the strongest death predictor before larger lung resections. Monaldi Arch Chest Dis. 2017;87:817.
22. Chan E, Giallauria F, Vigorito C, Smart NA. Exercise training in heart failure patients with preserved ejection fraction: a systematic review and meta-analysis. Monaldi Arch Chest Dis. 2016;86:759.

23. Xie B, Yan X, Cai X, Li J. Effects of high-intensity interval training on aerobic capacity in cardiac patients: a systematic review with meta-analysis. Biomed Res Int. 2017;2017:5420840.

24. Bott MJ, Patel AP, Crabtree TD, Morgensztern D, Robinson CG, Colditz GA, et al. Role for Surgical Resection in the Multidisciplinary Treatment of Stage IIIB Non-Small Cell Lung Cancer. Ann Thorac Surg. 2015;99:1921-8.

25. Bertolaccini L, Pardolesi A, Forti Parri SN, Bonfanti B, Brandolini J, Solli P. Surgical approaches in patients with oligometastatic non-small cell lung cancer. $J$ Thorac Dis. 2018;10:498-502.

26. Tarumi S, Yokomise H, Gotoh M, Kasai Y, Matsuura N, Chang SS, et al. Pulmonary rehabilitation during induction chemoradiotherapy for lung cancer improves pulmonary function. J Thorac Cardiovasc Surg. 2015;149:569-73.

27. Takeda S, Funakoshi Y, Kadota Y, Koma M, Maeda H, Kawamura S, et al. Fall in diffusing capacity associated with induction therapy for lung cancer: a predictor of postoperative complication? Ann Thorac Surg. 2006;82:232-6.

28. Margaritora S, Cesario A, Cusumano G, Cafarotti S, Corbo GM, Ferri L, et al. Is pulmonary function damaged by neoadjuvant lung cancer therapy? A comprehensive serial time-trend analysis of pulmonary function after induction radiochemotherapy plus surgery. J Thorac Cardiovasc Surg. 2010; 139:1457-63.

29. Fresard I, Licker M, Adler D, Lovis A, Robert J, Karenovics W, et al. Preoperative peak oxygen uptake in lung cancer subjects with neoadjuvant chemotherapy: A cross-sectional study. Resp Care. 2016;61:1059-66.

30. Cavalheri V, Granger C. Preoperative exercise training for patients with non-small cell lung cancer. Cochrane Database Syst Rev. 2017;6: CD012020.

31. Sebio Garcia R, Yanez Brage MI, Gimenez Moolhuyzen E, Granger CL, Denehy L. Functional and postoperative outcomes after preoperative exercise training in patients with lung cancer: a systematic review and meta-analysis. Interact Cardiovasc Thorac Surg. 2016;23:486-97.

32. Boujibar F, Bonnevie T, Debeaumont D, Bubenheim M, Cuvelier A, Peillon C, et al. Impact of prehabilitation on morbidity and mortality after pulmonary lobectomy by minimally invasive surgery: a cohort study. J Thorac Dis. 2018;10: $2240-8$.

Key Words: pulmonary rehabilitation, non-small cell lung cancer, lung resection, prehabilitation, ventilatory efficiency 
TABLE E1. Type of resection/intervention, postoperative length of stay, and complications for patients who underwent surgery at the end of prehabilitation $(n=39)$

\begin{tabular}{lc}
\hline \multicolumn{1}{c}{ Variable } & Value \\
\hline Type of resection* & \\
Wedge & $9(23.1)$ \\
Lobectomy & $25(64.1)$ \\
Bilobectomy & $2(5.1)$ \\
Pneumonectomy & $3(7.7)$ \\
Type of intervention* & \\
Thoracotomy & $8(20.5)$ \\
VATS/RATS & $31(79.5)$ \\
Length of stay, d $\dagger$ & $7.0(5.7-10.2)$ \\
Occurrence of complications* & $19(48.7)$ \\
Respiratory complications* & $17(43.6)$ \\
Clavien-Dindo classification $\leq 2 *$ & \\
Yes & $32(82.1)$ \\
No & $7(17.9)$ \\
\hline
\end{tabular}

VATS, Video-assisted thoracic surgery; RATS, robot-assisted thoracic surgery.

*Values expressed as $\mathrm{n}(\%)$. †Values expressed as median (25th-75th percentile).

TABLE E2. Analysis of postoperative length of stay and complications for patients who trained for less than or $\geq 15$ sessions

\begin{tabular}{lclc}
\hline \multicolumn{1}{c}{ Variable } & $\begin{array}{c}<\mathbf{1 5} \text { Sessions } \\
(\mathbf{n}=\mathbf{1 2})\end{array}$ & $\begin{array}{c}\geq \mathbf{1 5} \text { Sessions } \\
(\mathbf{n}=\mathbf{2 7})\end{array}$ & $\boldsymbol{P}$ value \\
\hline $\begin{array}{l}\text { Postoperative length of } \\
\text { stay, } \mathrm{d}^{*}\end{array}$ & $7.0(4.5-9.75)$ & $7.0(5.7-11.3)$ & .55 \\
Complications $\dagger$ & $7(58.3)$ & $12(44.4)$ & .50 \\
Respiratory complications $\dagger$ & $7(58.3)$ & $10(37.0)$ & .30 \\
$\begin{array}{l}\text { Clavien-Dindo classification } \\
\leq 2 \dagger\end{array}$ & $9(75.0)$ & $23(85.2)$ & .65 \\
\hline
\end{tabular}

*Values expressed as median (25th-75th percentile). †Values expressed as n (\%); Mann-Whitney test for postoperative length of stay, Fisher exact test for the proportion of patients with and without postoperative complications, and grading of severity. Clavien-Dindo classification $\leq 2$ indicates no complication or resolutive complication with medical treatment (no surgical treatment or unplanned intensive care). 